\title{
Correction to: Does flood experience modify risk preferences? Evidence from an artefactual field experiment in Vietnam
}

\section{Arnaud Reynaud $^{1,3} \cdot$ Cécile Aubert $^{2}$ (D)}

Published online: 21 January 2022

(c) International Association for the Study of Insurance Economics 2022

\section{Correction to: The Geneva Risk and Insurance Review (2020) 45:36-74 https://doi.org/10.1057/s10713-019-00044-w}

The article has been revised to include the following affiliation for Arnaud Reynaud:

University of Economics and Law Ho Chi Minh City and Vietnam Center of Research in Economics, Management and Environment (VCREME)

Additionally, the acknowledgements have been revised:

We acknowledge the support from the ANR under grant ANR-17-EUR-0010 (Investissements d'Avenir program) for traveling and conferences.

The original article has been corrected.

The original article can be found online at https://doi.org/10.1057/s10713-019-00044-w.

Arnaud Reynaud

arnaud.reynaud@inra.fr

Cécile Aubert

cecile.aubert@u-bordeaux.fr

1 Toulouse School of Economics, INRA, University of Toulouse Capitole, Toulouse, France

2 University of Bordeaux, GREThA, and Toulouse School of Economics, Bordeaux, France

3 University of Economics and Law Ho Chi Minh City and Vietnam Center of Research in Economics, Management and Environment (VCREME), Hanoi, Vietnam 